\title{
Geographical Analysis of the Patterns of Healthcare Facilities and HIV/ AIDS Response Sites in Benue State, Nigeria
}

\author{
Oyekanmi Isaac Babatimehin ${ }^{*}, 1$, Nancy-Twakor Ese Nelson ${ }^{2}$, Raphael O. Oyinloye ${ }^{3}$, \\ Nathaniel Olugbade Adeoye ${ }^{4}$, Olalekan J. Taiwo ${ }^{5}$ and Jesutowo Daniel Ige ${ }^{1}$
}

\author{
${ }^{I}$ Department of Geography, Obafemi Awolowo University, Ile-Ife, Nigeria \\ ${ }^{2}$ Management Science for Health, Abuja, Nigeria \\ ${ }^{3}$ Regional Centre for Training in Aerospace Surveys, Obafemi Awolowo University Campus, Ile-Ife, Nigeria \\ ${ }^{4}$ Department of Geography, Obafemi Awolowo University, Ile-Ife, Nigeria \\ ${ }^{5}$ Department of Geography, University of Ibadan, Ibadan, Nigeria
}

\begin{abstract}
This study analysed the spatial patterns and characteristics of healthcare facilities and HIV/AIDS response sites; and the relationship between the distribution of population and healthcare facilities/HIV/AIDS response sites in Benue State, the State with the highest record of HIV/AIDS in Nigeria. Primary and secondary data were used for the study. GPS receiver was used to obtain the geographic coordinates of healthcare facilities and HIV/AIDS response sites; and questionnaire to acquire attribute data of the sites. The secondary data used included the list of all healthcare facilities at community and LGA levels, maps, and the population of the state. The spatial analyses of the phenomena of interest were done based on the LGAs. All the 1243 healthcare facilities in the 23 LGAs of the state were captured in the study. Four key HIV/AIDS services (VCT, PMTCT, ART and HBC) were purposively selected for the study. The analogue map of Benue State was processed and used for various GIS analyses and cartographic enhancement for the purpose of report presentation. The study identified three categories of Healthcare Facilities (primary, secondary and tertiary) in the state. There existed spatial variation in the distribution of the various healthcare facilities in the state. The PHCs were observed to be more widely distributed in the state $(93.4 \%)$ than the SHCs $(6.3 \%)$ and THCs $(0.2 \%)$ which were observed to be largely concentrated in the urban LGAs. Also, specialised HIV/AIDS services like PMTCT and ART were observed to be concentrated in the urban LGAs. The population/Facility ratio for PHCF, SHCF and THCF were 2,371:1; 34,413:1; and 1,376,539:1 respectively. There existed a direct relationship between both population and distribution of healthcare facilities $(r=0.694, p>0.5)$; and population and the distribution of HIV/AIDS response sites $(r=0.664, p>0.5)$ in the state. The study concluded that the problem of HIV/AIDS in Benue State is more engendered by the paucity of information about the availability of response sites than their inadequacy; and recommends that a robust database for healthcare facilities and HIV/AIDS response sites be developed at all levels in order to enhance information flow to policy formulators and by extension people who require healthcare and HIV/AIDS services.
\end{abstract}

Keywords: Benue state, healthcare facilities, HIV/AIDS response sites, Nigeria, population.

\section{INTRODUCTION}

The distribution questions have continued to be vital in both academic and policy formulation circles because it is recognised that despite the provision of additional facilities in different locations, the question of the population served by these facilities in still very crucial in the assessment of the efficiency and optimality of such facilities [1].

The location of healthcare facilities, within which the Human Immuno-deficiency Virus and the Acquired Immune Deficiency Syndrome (HIV/AIDS) response sites are mostly located, is an important aspect of healthcare provision. The challenge of HIV/AIDS has been an issue of global concern, especially in developing and resource constrained countries

*Address correspondence to this author at the Department of Geography, Obafemi Awolowo University, Ile-Ife, Nigeria; Tel: +2348033728678;

E-mail: oyebabatimehin@yahoo.com of Africa, which today is the continent with the highest incidence of the disease [2].

In Nigeria, the first case of AIDS was identified in the mid-1980s and HIV incidence in the country reached a peak of 5.8\% (among women attending antenatal) in 2001 [2]. Hence, Nigeria became the country with the third highest level of infection in the world, coming behind India and South Africa respectively. Spatio-temporal variations exist in the prevalence of the disease. As at 2001, estimates showed that the incidence of the disease in the North-Central geopolitical zone of the country was $7.0 \% ; 5.8 \%$ in the NorthEast and South-South respectively, $4.2 \%$ in the South-East, $2.7 \%$ in the North-West and $2.3 \%$ in the South-West. By 2006 , the incidence had reduced to $6.1 \%$ in the NorthCentral, $4.3 \%$ in the North-East and 5.3\% in the South-South zone. However, in the South-East, North-West and SouthWest, the prevalence of the disease had increased to $4.7 \%$, $3.5 \%$ and $2.6 \%$ respectively [2]. Estimates showed that as at 
2006, there were about 3,000,000 adults living with HIV/AIDS in Nigeria, about 220,000 deaths from HIV/AIDS and about 930,000 children orphaned by AIDS in Nigeria. In addition, there were about 240,000 HIV positive children, about 9,000 of who contracted the virus from their mothers through the mother-to-child-transmission [3]. In 2010, there were estimated 3.14 million people living with AIDS, 2.1 million deaths from AIDS, 2.2 children orphaned by AIDS and about 1.5 million in need of antiretroviral therapy. Despite these staggering figures, however, recent records indicate a reversal in the prevalence of HIV/AIDS in Nigeria from $5.8 \%$ in 2001 to $4.1 \%$ in 2010 [4].

The care, treatment and legislation protecting HIV/AIDS patients have been a global issue, particularly, in Nigeria [5]. Although there is no cure currently available for HIV/AIDS $[6,7]$; the availability of care and support for people living with HIV/AIDS (PLWHA) in developed countries have proven to be effective in reducing morbidity and mortality associated with HIV/AIDS [6-9].

In 2010 the National Action Committee on AIDS launched a comprehensive national strategic framework to cover the period between 2010 and 2015. This strategic plan requires an estimated 756 billion naira (around USD 5 billion) to implement. Some of the objectives included in the framework are to reach $80 \%$ of sexually active adults and $80 \%$ of most at-risk populations with HIV counselling and testing by 2015 ; ensure that $80 \%$ of eligible adults and $100 \%$ of eligible children are receiving ART by 2015; and to improve access to quality care and support services to at least $50 \%$ of people living with HIV by 2015 [10].

However, one of the contemporary challenges today in the treatment of HIV/AIDS is the logistics of enhancing access to care and treatment for PLWHA in developing countries where approximately $95 \%$ of world's population living with HIV/AIDS reside [11, 12].

In spite of the global and national fight against HIV/AIDS and the huge amount voted to combat the disease, literature reveals that a small percentage of people in need of HIV/AIDS services in the developing countries, Nigeria inclusive, have access to them [12-15]. This could be partly attributable to the paucity of information on locations where HIV/AIDS services are available. Most studies on HIV/AIDS in Nigeria are centred on prevention, public awareness strategies and some related issues such as assessing the impacts of these strategies. There have also been studies on the socio-economic burden and cost of various aspects of the disease [16, 17]. Other studies on care and treatment in Nigeria have centred on the evaluation of governments' policies. In addition, monitoring and evaluation programmes have been conducted, mostly by donor agencies, on HIV/AIDS services provision in both rural and urban parts of Nigeria.

Questions about the locational pattern, accessibility and utilisation of HIV/AIDS response sites have remained a daunting challenge both to policy makers and researchers alike in Nigeria largely because of paucity of data. The number of voluntary counselling and testing (VCT) centres and their patronage; the total number of centres caring for orphans and vulnerable children and the number of those cared for as well as the level of patronage of centres for treatment of opportunistic infections have not been ascertained [15]. Hence, this study analyses the spatial patterns of HIV/AIDS response sites in Benue State, with a view to understanding the distributional inequality in the allocation of treatment centres.

The study hypothesizes that there exist a direct relationship between population and distribution healthcare facilities; and population and distribution of HIV/AIDS response sites in Benue State.

\section{METHODOLOGY}

\subsection{The Study Area}

Benue State, lies between Latitudes $6^{\circ} 25^{\prime} 54^{\prime \prime}$ and $8^{\circ} 9^{\prime}$ $34^{\prime \prime}$ North of the Equator and Longitudes $7^{\circ} 29^{\prime} 20^{\prime \prime}$ and $9^{\circ}$ 56' 18" East of the Greenwich Meridian, covering a land area of about $30,800 \mathrm{~km}^{2}$. It is situated within the Lower Benue Trough which separates the north-central highlands from the south-eastern scarplands and the Cross River Plains. The State is located in the North Central geo-political zone of Nigeria, and bordered by Nassarawa State in the north, Taraba State in the east, Enugu, Ebonyi and Cross River States in the south and Kogi State in the west (see Fig. 1).

\subsection{Data Sources and Acquisition}

Primary and secondary data were used for the study. The primary data involved the use of Global Positioning System (GPS) receiver to obtain the geographic coordinates of the location of healthcare facilities and HIV/AIDS response sites. The questionnaire, among other issues, sought information about the characteristics of each facility, and type of HIV/AIDS services provided. The secondary data included the list and addresses of all the healthcare facilities (HCF) in the state obtained from the State's Ministry of Health. Also the population figures of the State and LGAs were derived from the records of the National Population Commission, Abuja.

\subsection{Data Collection Procedure}

The unit of spatial analyses of the patterns of HIV/AIDS treatment centres was conducted at the LGA level. All the 1243 healthcare facilities in the 23 LGAs of the State were captured in the study. Using the list of all registered health care facilities obtained from the State Ministry of Health, which contains the name and address of each facility, it was easy to navigate to where the facilities were located. For every facility mapped; a questionnaire was administered to the proprietor or the head of the facility.

Four HIV/AIDS services were purposively selected for the study, these were voluntary counselling and testing (VCT), prevention of mother to child transmission (PMTCT), administration of anti-retroviral therapy (ART), and home based care (HBC).

\subsection{Data Preparation and Analysis}

The analogue map of Benue State was scanned and exported to ArcGIS software, where it was georeferenced using the Universal Transverse Mercator, Zone $32 \mathrm{~N}$ 


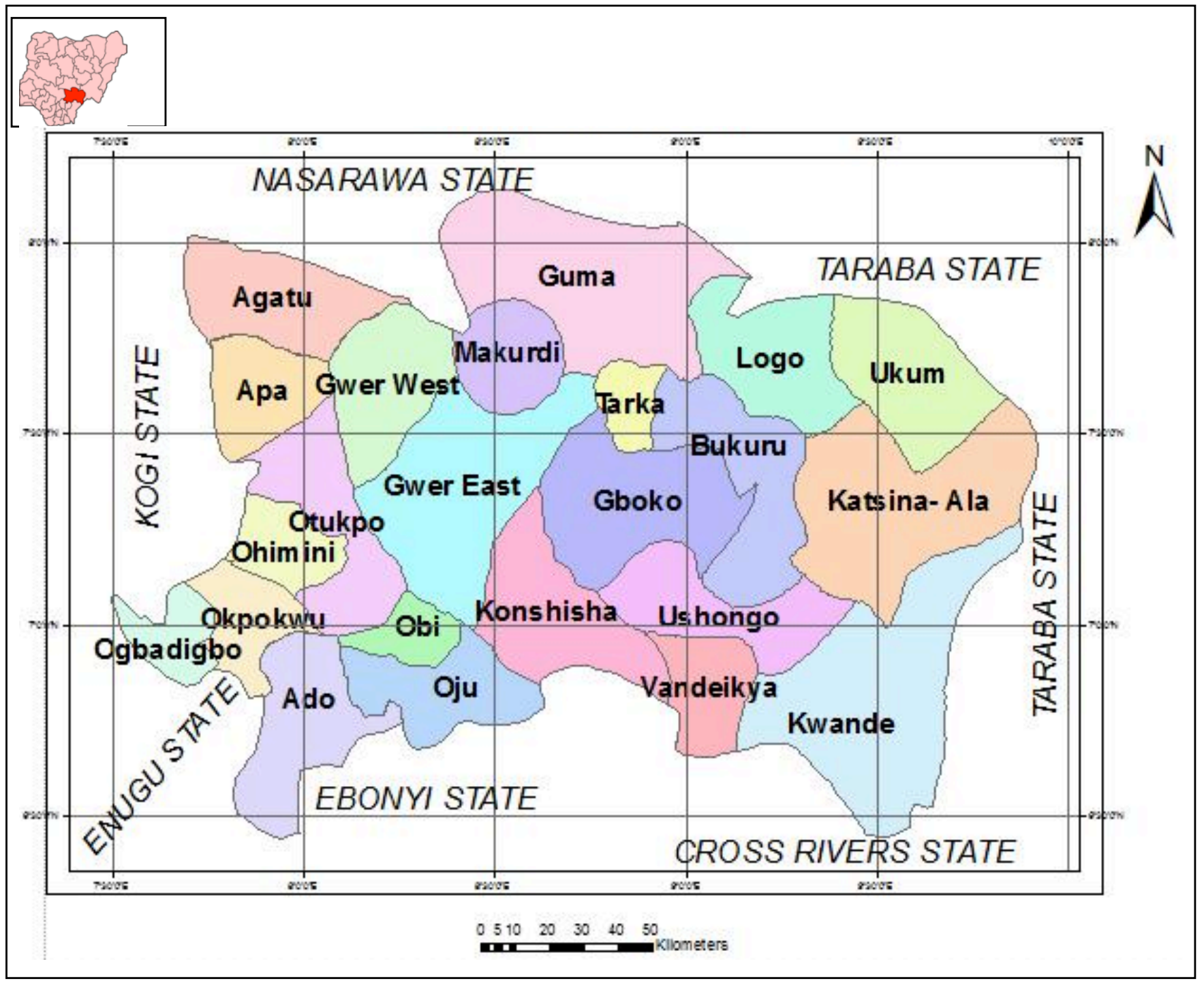

Fig. (1). Study Area - Benue State. [Source: Authors].

(Minna). Thereafter, relevant layers of the map were digitised and their various attribute tables created. The positional and attribute data of the HCFs and HIV/AIDS response sites hitherto structured in Microsoft Office Access were imported into ArcGIS and overlaid on the shape files already created. This was followed by the various GIS analysis and cartographic enhancement. These involved the use of various visual variables and appropriate visual perception. Dot maps, pie and bar charts and other relevant tools were used to represent phenomena of interest on maps. Correlation analysis was carried out to determine the nature of relationship between population and distribution of HCFs and HIV/AIDS response sites.

The spatial pattern of the HCFs and HIV/AIDS response sites and their characteristics in Benue State were analysed using both GIS tools and simple frequency count. The geographic coordinates of all the HCFs were located on the LGA map of the State to show a quick view of the spatial patterns. Then, query analyses were carried out to represent the various categories (Primary, secondary and tertiary) of HCF. Furthermore, the frequency distribution of the facilities was performed and discussed. This was done in phases, first, the general patterns of HCFs, and then the various tiers. Thereafter, the spatial patterns of specific HIV/AIDS response sites (VCT, PMTCT, ART, and HBC) were analysed and represented cartographically.

\section{RESULTS AND DISCUSSION}

\subsection{Spatial Distribution of Healthcare Facilities in Benue State}

The location of the 1,243 HCFs in the state is shown in Fig. (2). The HCFs were made up of three different categories representing the three tiers of HCF in Nigeria primary $(93.4 \%)$, secondary $(6.3 \%)$ and tertiary $(0.2 \%)$, (see Table 1). In all, Gboko LGA with 107 (8.6\%) HCFs had the highest number in the State. This was followed by Ushongo LGA with 80 (6.4\%) and Otukpo with 78 (6.3\%). Makurdi, Konshisha and Ukum LGAs accounted for 73 (5.9\%), 68 (5.5\%) and 67 (5.4\%) respectively. Ado LGA had $13(1.0 \%)$ HCFs, the least in the State. 


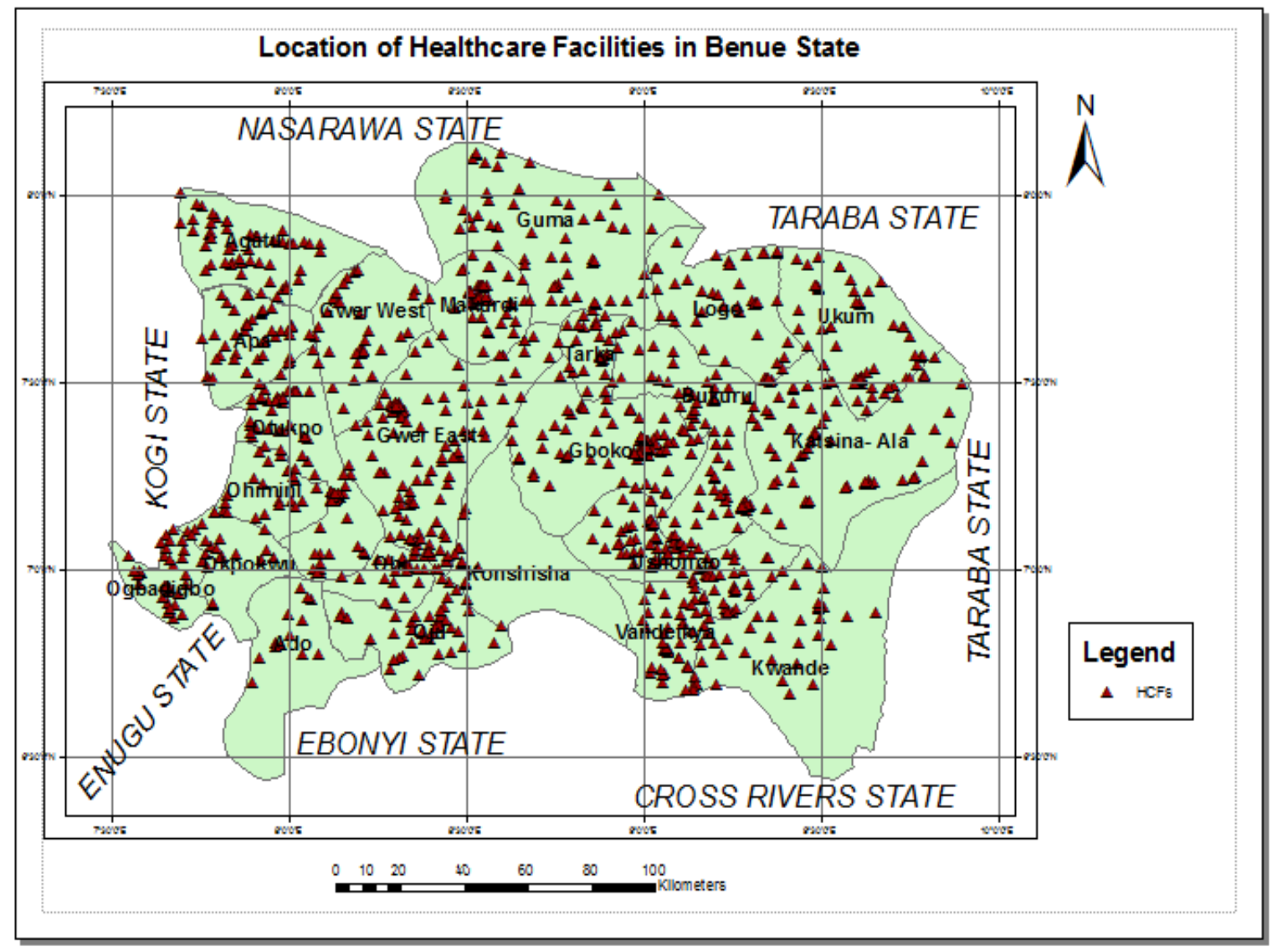

Fig. (2). Location of Healthcare Facilities in Benue State. [Source: Authors' analysis].

In order to depict the distribution of HCFs according to the various tiers, the number of the various categories of HCFs in each LGA were aggregated and used in showing the LGA scenario. Data showed that the Primary Healthcare Facilities (PHCFs) were more widely distributed across the various LGAs than both the Secondary Healthcare Facilities (SHCFs) and the Tertiary Healthcare Facilities (THCFs), which were concentrated in mostly urban LGAs such as Makurdi, Gboko and Otukpo.

Specifically, Makurdi LGA had 21 SHCFs which represented $26.3 \%$ of the 80 SHCFs in the State. This was followed by Gboko 16 (20\%), and Otukpo11 (13.8\%). No SHCF was recorded in Ado, Agatu, Guma, Konshish and Ohimini. There were only two THCFs in the State and the two were located at Makurdi, the State capital (see Fig. 3).

\subsection{Spatial Patterns of HIV/AIDS Response Sites}

Four HIV/AIDS services were purposively selected for analysis. These are prevention of mother to child transmission (PMTCT), anti-retroviral therapy (ART), HIV voluntary counselling and testing (VCT) and home based care for HIV/AIDS sufferers (HBC). These services were mostly located within HCFs and there were occasions in which a given facility would provide more than one service simultaneously.

VCT was the most widely provided HIV/AIDS service. It was the only service provided in all the LGAs. On the other hand, provision of the relatively more specialised services like PMTCT and ART were concentrated in the urban LGAs.
For instance, $57 \%$ of all the PMTCT centres in the State were located at Makurdi and Gboko with Makurdi alone accounting for $47 \%$ of the total. In addition, the two urban LGAs accommodated $51 \%$ of all the ART centres in the State (see Table 2 and Figs. 4-8).

\subsection{Relationship between Population and Distribution of Facilities}

The population/facility ratio in each LGA and the State in general is presented in Table 3. This was done for every category of HCF and all HCFs put together. On the average, there were 2,215 persons to every HCF in the State. The highest population/facility ratio was recorded in Ado LGA $(8,011: 1)$. This was followed by Kwande $(4,624: 1)$, Makurdi $(3,286: 1)$, and Okpokuru $(3,223: 1)$ LGAs respectively. The LGAs with the least ratio were Apa $(1,048: 1)$, Ohimini $(1,158: 1)$, Agatu $(1,176: 1)$ and Logo $(1,273: 1)$. Incidentally, these were some of the LGAs with the least population in the State (see Fig. 9). The pattern observed for the total number of HCFs is not radically different from what was obtained for the PHCFs. The urban LGAs, particularly Makurdi, did not present any unique advantage over the others in terms of the ratio for PHCFs (see Fig. 10).

However, this is different in the case of SHCFs where the urban LGAs of Otukpo, Makurdi, and Gboko recorded the lowest population/facility ratio $(8,139: 1,12,690: 1$, and 14,993:1) respectively. The ratio recorded by these LGA were far below the State average which was 34,413 persons 
Table 1. Distribution of HCFs according to Tier and LGA.

\begin{tabular}{|c|c|c|c|c|c|c|c|c|}
\hline \multirow[t]{2}{*}{ LGA } & \multicolumn{2}{|c|}{ Primary } & \multicolumn{2}{|c|}{ Secondary } & \multicolumn{2}{|c|}{ Tertiary } & \multicolumn{2}{|c|}{ Total } \\
\hline & No & $\%$ & No & $\%$ & No & $\%$ & No & $\%$ \\
\hline Ado & 13 & 1.1 & 0 & 0.0 & 0 & 0.0 & 13 & 1.0 \\
\hline Agatu & 46 & 3.9 & 0 & 0.0 & 0 & 0.0 & 46 & 3.7 \\
\hline Buruku & 45 & 3.9 & 1 & 1.3 & 0 & 0.0 & 46 & 3.7 \\
\hline Gboko & 91 & 7.8 & 16 & 20.0 & 0 & 0.0 & 107 & 8.6 \\
\hline Guma & 69 & 5.9 & 0 & 0.0 & 0 & 0.0 & 69 & 5.6 \\
\hline Gwer East & 55 & 4.7 & 2 & 2.5 & 0 & 0.0 & 57 & 4.6 \\
\hline Kwande & 37 & 3.3 & 2 & 2.5 & 0 & 0.0 & 39 & 3.1 \\
\hline Logo & 57 & 4.9 & 1 & 1.3 & 0 & 0.0 & 58 & 4.7 \\
\hline Makurdi & 50 & 4.4 & 21 & 26.3 & 2 & 100 & 73 & 5.9 \\
\hline Obi & 26 & 2.2 & 1 & 1.3 & 0 & 0.0 & 27 & 2.2 \\
\hline Ogadibo & 60 & 5.2 & 1 & 1.3 & 0 & 0.0 & 61 & 4.9 \\
\hline Ohimini & 29 & 2.5 & 0 & 0.0 & 0 & 0.0 & 29 & 2.3 \\
\hline OJU & 46 & 3.9 & 4 & 5.0 & 0 & 0.0 & 50 & 4.0 \\
\hline Vandeikya & 56 & 4.8 & 3 & 3.8 & 0 & 0.0 & 59 & 4.7 \\
\hline Total & 1,161 & 100.0 & 80 & 100.0 & 2 & 100 & 1,243 & 100 \\
\hline$\%$ of Total & & 93.4 & & 6.4 & & 0.2 & & 100 \\
\hline
\end{tabular}

Source: Fieldwork, 2007

per facility $(34,413: 1)$. It has already been established that the two THCFs in the State were located in the State capital (Table 1).

In order to ascertain the relationship between population and the distribution of HCFs and HIV/AIDS in the State, the Pearson's moment correlation coefficient was used. The correlation coefficient $\left(r=0.694, r^{2}=0.482, p>0.05\right)$, implies a direct relationship between population and healthcare facilities. Although direct, but the relationship is rather weak as only $48 \%$ of HCFs is determined by population, leaving $52 \%$ to other factors. In a similar vein, the result of correlation analysis between population and HIV/AIDS response site is direct $\left(r=0.664, r^{2}=0.441, p>\right.$ $0.05)$. This also implies a rather weak relationship, meaning that there are other important locational factors of HIV/AIDS response facilities in the state other than population.

\section{CONCLUSION AND RECOMMENDATION}

This study has shown that there exists a direct (though weak) relationship between population distribution and number of healthcare facilities on the one hand and the number of HIV/AIDS response sites on the other. The study concludes that the problems of HIV/AIDS in Benue State, Nigeria is not as a result of the inadequacy of HCFs and HIV/AIDS response services but rather, the paucity of information on their distribution. The study, therefore, recommends that a robust database for healthcare facilities should be developed at all administrative levels. This will provide a framework for effective management of all aspects of HCFs and HIV/AIDS services. In addition, it will enhance information flow to people who require healthcare services especially the specialised ones and aid in locational decisionmaking. 


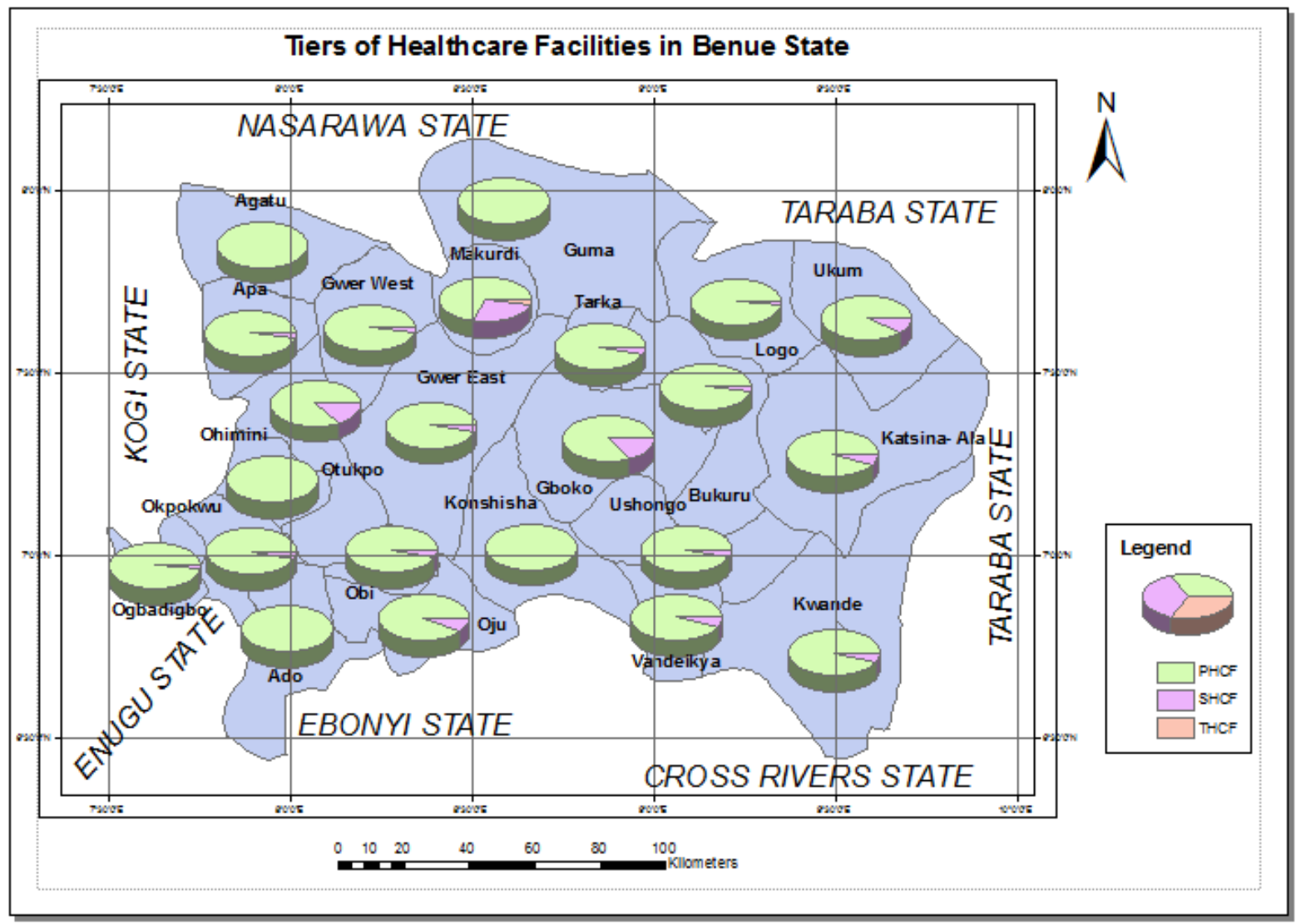

Fig. (3). Distribution of HCFs according to Tier and LGA. [Source: Authors' analysis].

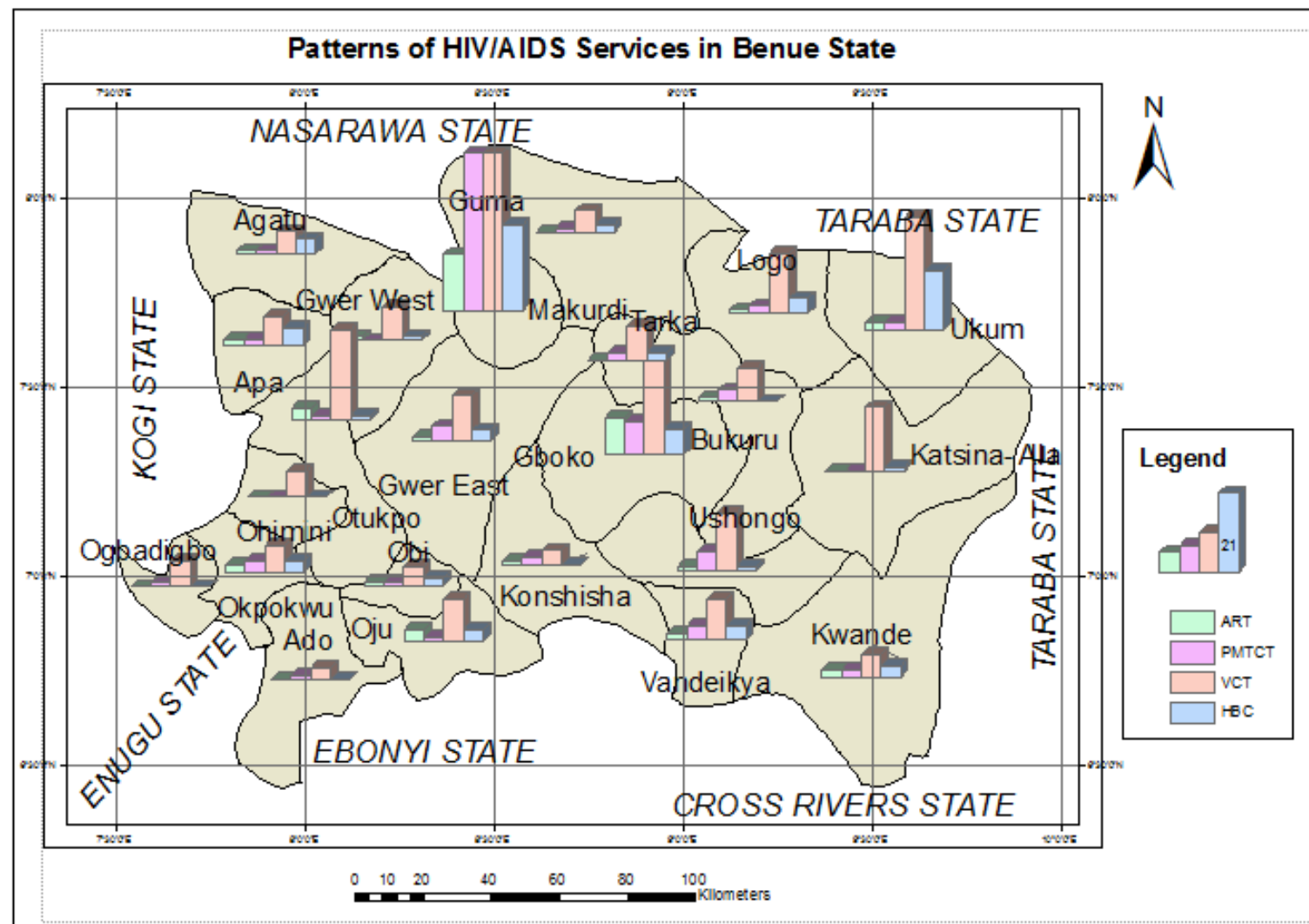

Fig. (4). Spatial Variations in HIV/AIDS Services Provision. [Source: Authors' analysis]. 


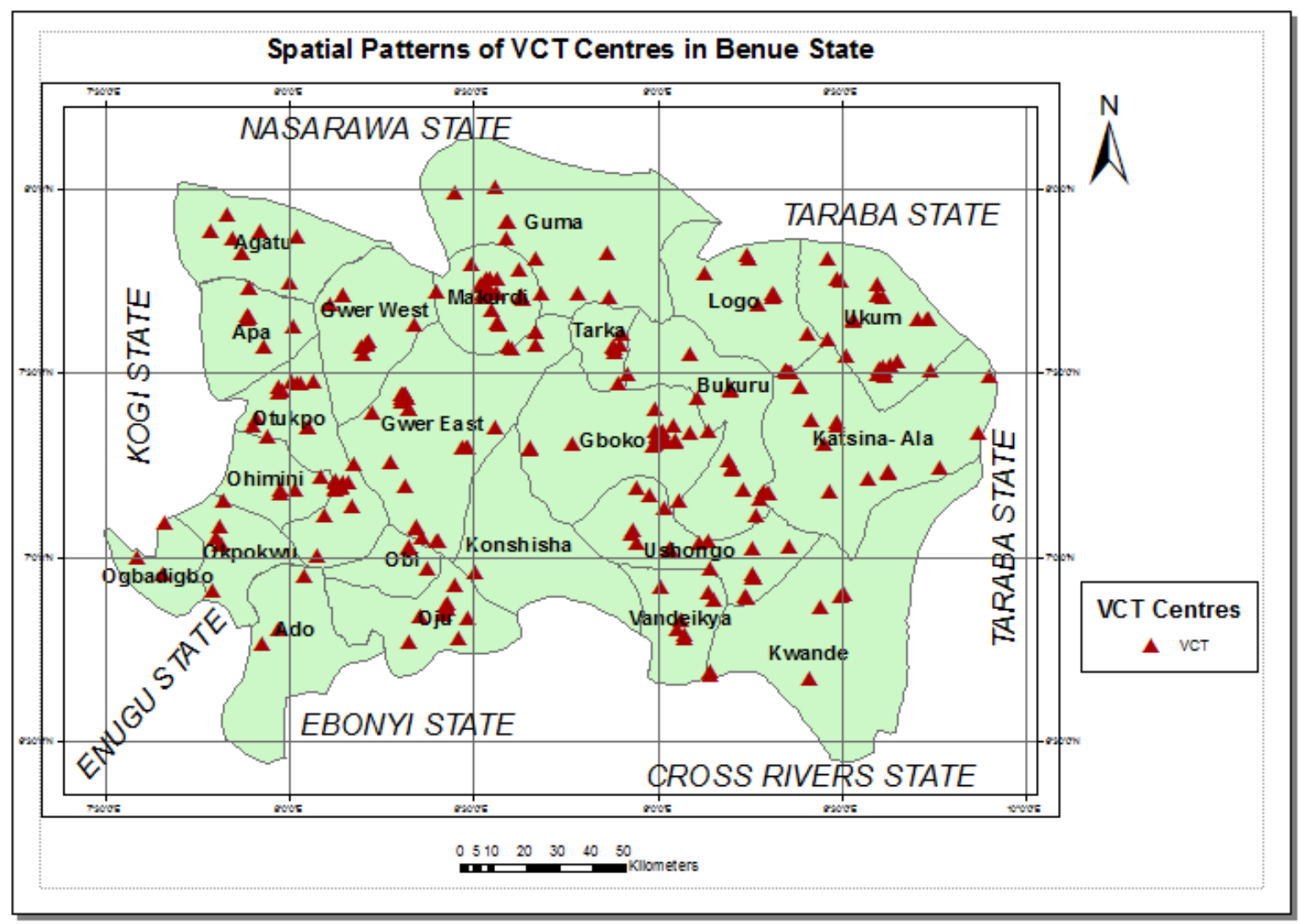

Fig. (5). Distribution of VCT Centres in Benue State. [Source: Authors' analysis].

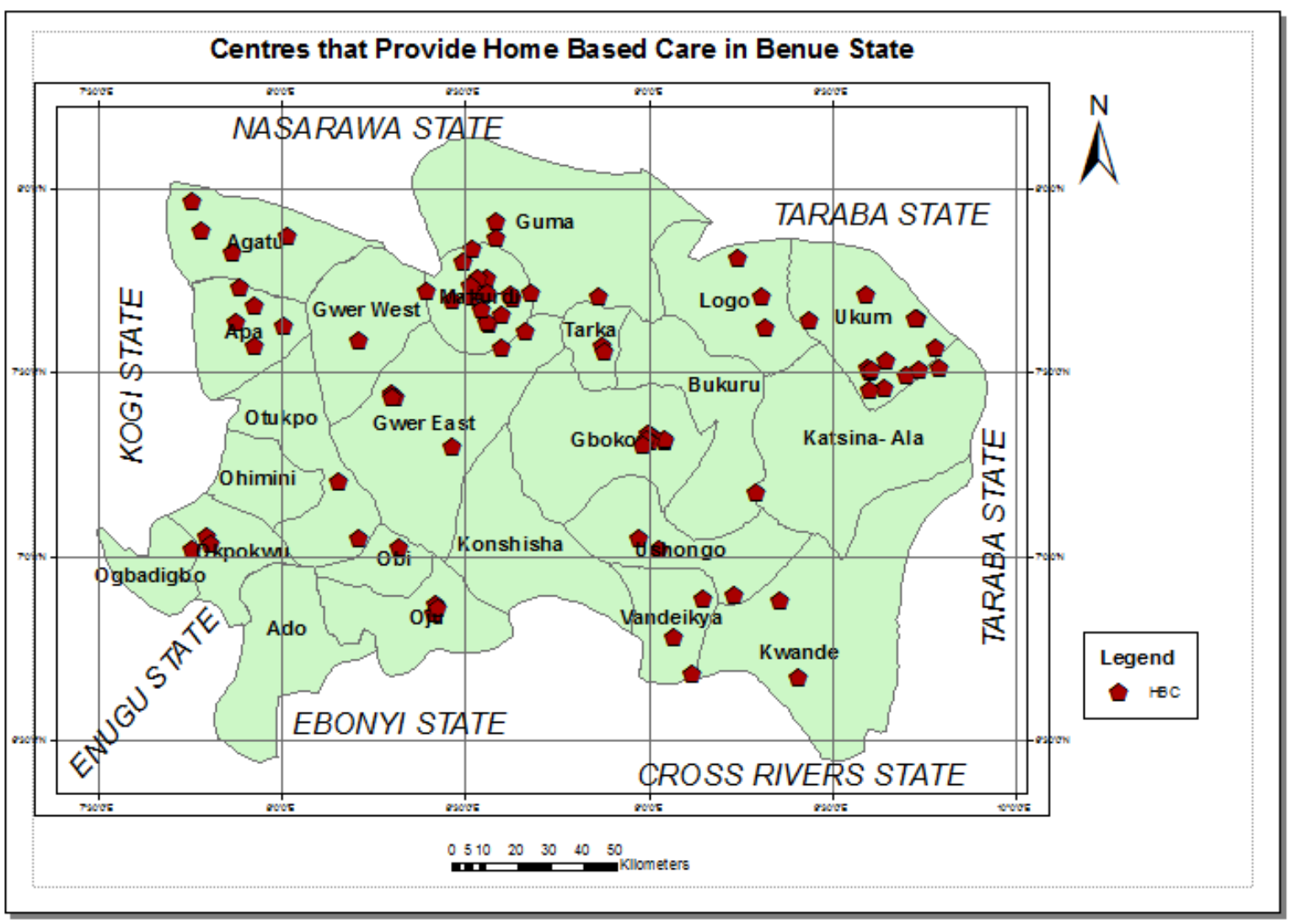

Fig. (6). Distribution of Centres that Provide HBC in Benue State. Source: [Authors' analysis]. 


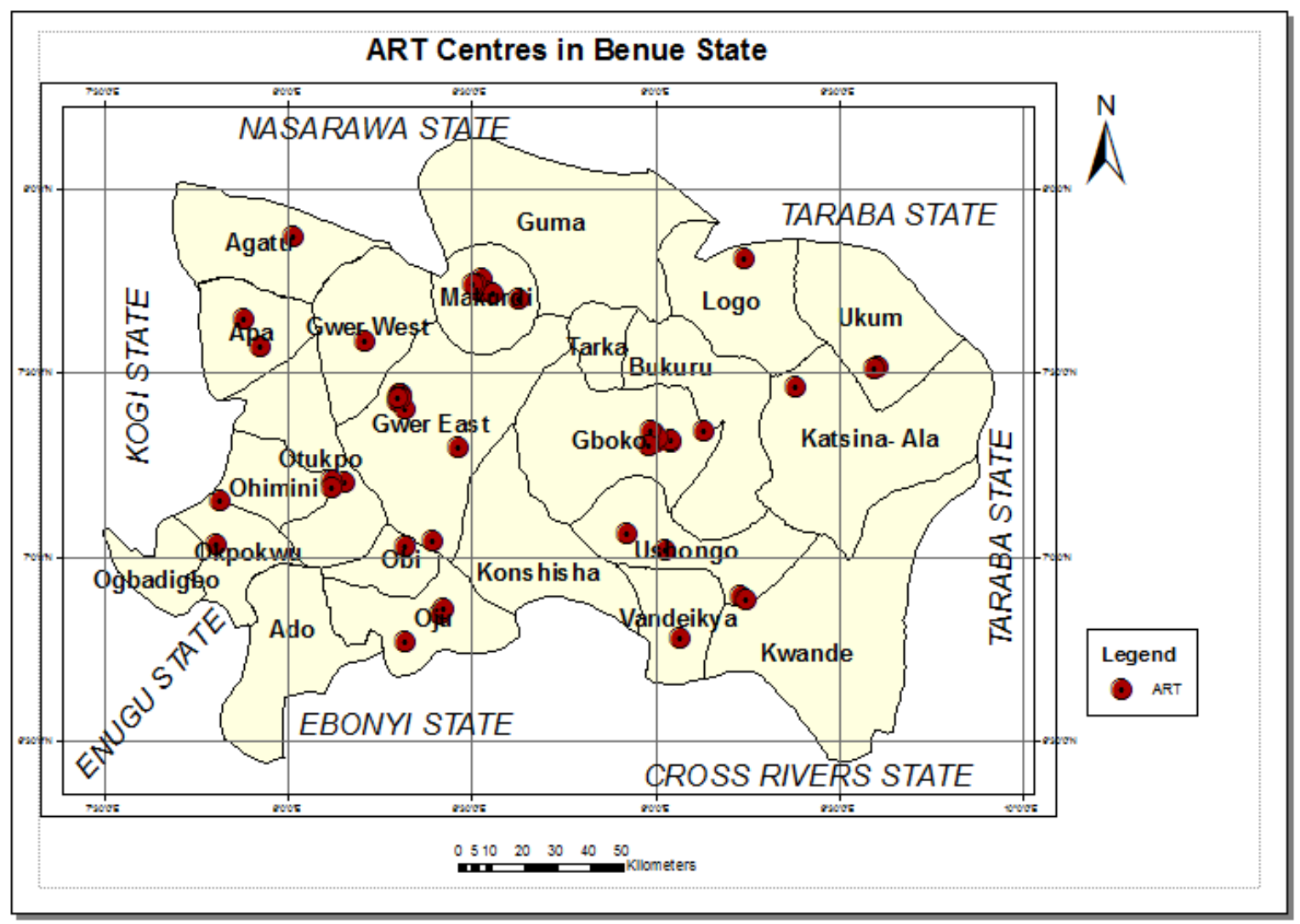

Fig. (7). Distribution of ART Centres in Benue State. [Source: Authors' analysis].

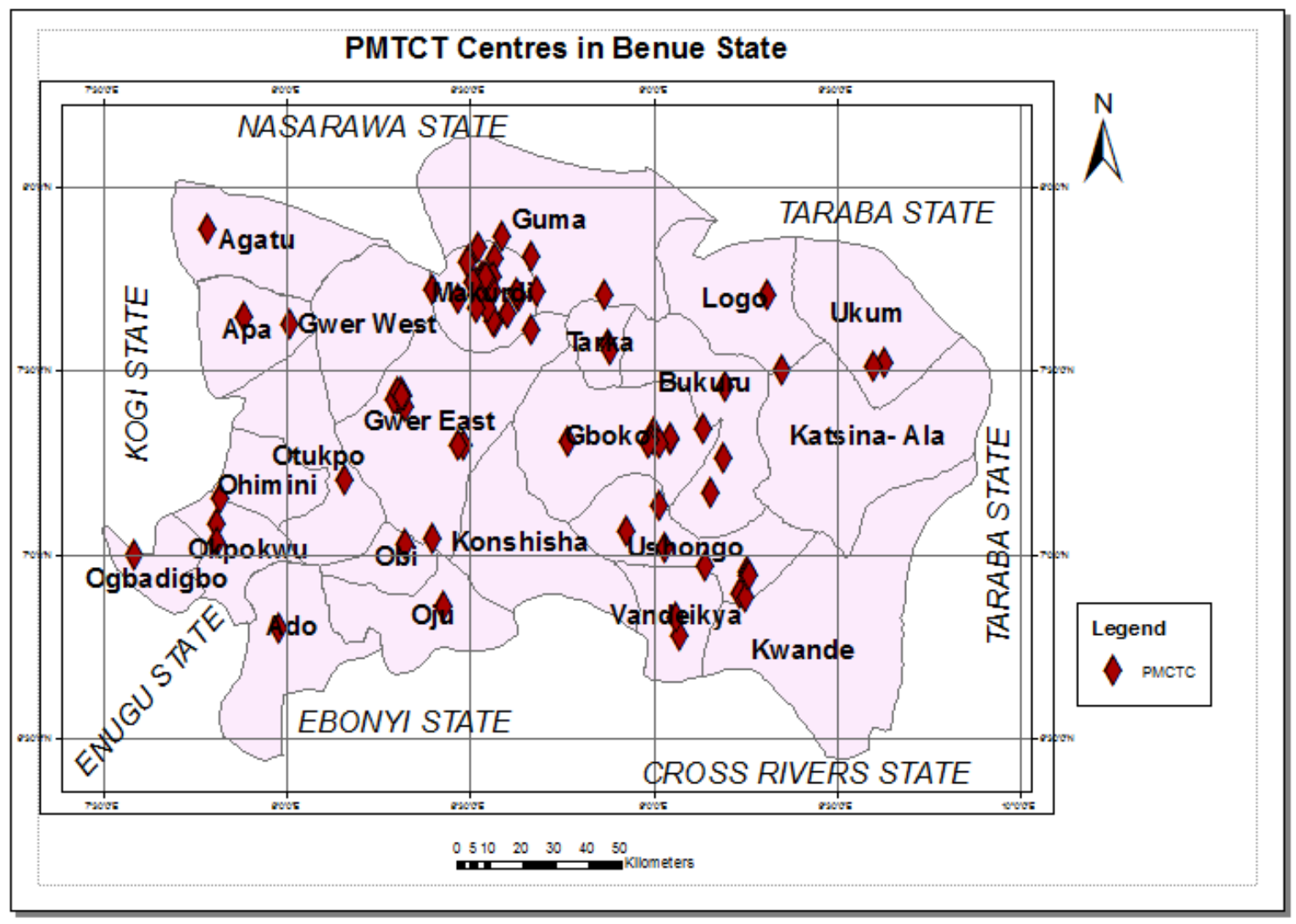

Fig. (8). Distribution of PMTCT Centres in Benue State. Source: [Authors' analysis]. 
Table 2. Distribution of HIV/AIDS services in Benue state.

\begin{tabular}{|c|c|c|c|c|c|c|c|c|c|c|}
\hline \multirow{3}{*}{ LGA } & \multicolumn{8}{|c|}{ HIV/AIDS Services } & \multicolumn{2}{|c|}{ Total } \\
\hline & \multicolumn{2}{|c|}{ VCT } & \multicolumn{2}{|c|}{ PMTCT } & \multicolumn{2}{|c|}{ ART } & \multicolumn{2}{|c|}{ HBC } & \multirow{2}{*}{ No } & \multirow{2}{*}{$\%$} \\
\hline & No & $\%$ & No & $\%$ & No & $\%$ & No & $\%$ & & \\
\hline Ado & 3 & 1.0 & 1 & 1.1 & 0 & 0 & 0 & 0 & 4 & 0.8 \\
\hline Agatu & 6 & 2.1 & 1 & 1.1 & 1 & 2.0 & 4 & 4.7 & 12 & 2.3 \\
\hline Apa & 8 & 2.8 & 2 & 2.3 & 2 & 4.1 & 5 & 5.9 & 17 & 3.3 \\
\hline Bukuru & 9 & 3.1 & 3 & 3.4 & 1 & 2.0 & 0 & 0 & 13 & 2.5 \\
\hline Gboko & 25 & 8.7 & 9 & 10. & 10 & 20.4 & 7 & 8.2 & 51 & 10.0 \\
\hline Guma & 6 & 2.1 & 1 & 1.1 & 0 & 0 & 2 & 2.4 & 9 & 1.8 \\
\hline Gwer East & 12 & 4.2 & 4 & 4.5 & 1 & 2.0 & 3 & 3.5 & 20 & 3.9 \\
\hline Gwer West & 9 & 3.1 & 0 & 0 & 1 & 2.0 & 1 & 1.2 & 11 & 2.1 \\
\hline Katsina-Ala & 17 & 5.9 & 0 & 0 & 0 & 0 & 1 & 1.2 & 18 & 3.5 \\
\hline Konshisha & 4 & 1.4 & 2 & 2.3 & 1 & 2.0 & 0 & 0 & 7 & 1.4 \\
\hline Kwande & 6 & 2.1 & 2 & 2.3 & 2 & 4.1 & 3 & 3.5 & 13 & 2.5 \\
\hline Logo & 16 & 5.5 & 2 & 2.3 & 1 & 2.0 & 4 & 4.7 & 23 & 4.5 \\
\hline Makurdi & 42 & 14.5 & 42 & 47.2 & 15 & 30.6 & 23 & 27.1 & 122 & 23.8 \\
\hline Obi & 5 & 1.7 & 1 & 1.1 & 1 & 2.0 & 2 & 2.4 & 9 & 1.8 \\
\hline Ogbadibo & 7 & 2.4 & 1 & 1.1 & 0 & 0 & 0 & 0 & 8 & 1.6 \\
\hline Ohinimi & 7 & 2.4 & 0 & 0 & 0 & 0 & 0 & 0 & 7 & 1.4 \\
\hline Oju & 11 & 3.8 & 1 & 1.1 & 3 & 6.1 & 3 & 3.5 & 18 & 3.5 \\
\hline Okpokuru & 7 & 2.4 & 3 & 3.4 & 2 & 4.1 & 3 & 3.5 & 15 & 2.9 \\
\hline Otukpo & 24 & 8.3 & 1 & 1.1 & 3 & 6.1 & 1 & 1.2 & 29 & 5.7 \\
\hline Tarka & 9 & 3.1 & 2 & 2.3 & 0 & 0 & 2 & 2.4 & 13 & 2.5 \\
\hline Ukum & 30 & 10.4 & 2 & 2.3 & 2 & 4.1 & 16 & 18.8 & 50 & 9.8 \\
\hline Ushongo & 15 & 5.2 & 5 & 5.6 & 1 & 2.0 & 1 & 1.2 & 22 & 4.3 \\
\hline Vandeikya & 11 & 3.8 & 4 & 4.5 & 2 & 4.1 & 4 & 4.7 & 21 & 4.1 \\
\hline Total & 289 & 100 & 89 & 100 & 49 & 100 & 85 & 100 & 512 & 100 \\
\hline
\end{tabular}

Source: Field work, 2007.

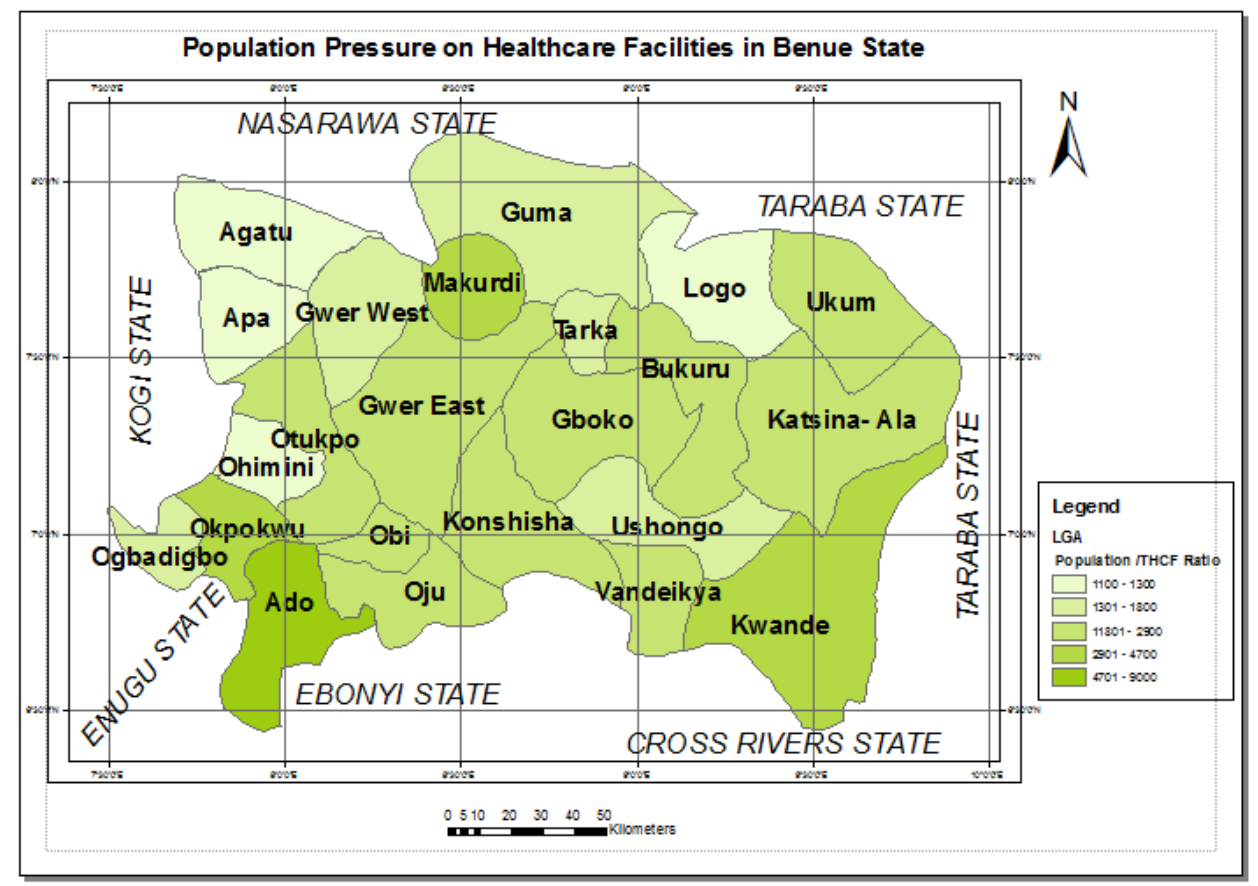

Fig. (9). Population/total healthcare facility ratio. [Source: Authors' analysis]. 
Table 3. Population-healthcare facility ratio.

\begin{tabular}{|c|c|c|c|c|c|c|c|c|c|}
\hline \multirow{3}{*}{ LGA } & \multicolumn{6}{|c|}{ HCF Tier } & \multirow{2}{*}{\multicolumn{2}{|c|}{ Total }} & \multirow{3}{*}{ Population } \\
\hline & \multicolumn{2}{|c|}{ Primary } & \multicolumn{2}{|c|}{ Secondary } & \multicolumn{2}{|c|}{ Tertiary } & & & \\
\hline & No & Pop/PHCF & No & Pop/SHCF & No & Pop/THCF & No & Pop/Total HCF & \\
\hline Ado & 13 & 8,011 & 0 & - & 0 & - & 13 & 8011 & 104,137 \\
\hline Agatu & 46 & 1,176 & 0 & - & 0 & - & 46 & 1176 & 54,101 \\
\hline Apa & 49 & 1,070 & 1 & 52,417 & 0 & - & 50 & 1048 & 52,417 \\
\hline Buruku & 45 & 2,884 & 1 & 129,790 & 0 & - & 46 & 2822 & 129,790 \\
\hline Gboko & 91 & 2,928 & 16 & 16,656 & 0 & - & 107 & 2491 & 266,490 \\
\hline Guma & 69 & 1,686 & 0 & - & 0 & - & 69 & 1686 & 116,336 \\
\hline Gwer East & 55 & 2,139 & 2 & 58,815 & 0 & - & 57 & 2064 & 117,630 \\
\hline Gwer West & 41 & 1,819 & 1 & 74,586 & 0 & - & 42 & 1776 & 74,586 \\
\hline Katsina-Ala & 63 & 2,560 & 4 & 40,320 & 0 & - & 67 & 2407 & 161,281 \\
\hline Konshish & 68 & 2,141 & 0 & - & 0 & - & 68 & 2141 & 145,614 \\
\hline Kwande & 37 & 4,874 & 2 & 90,164 & 0 & - & 39 & 4624 & 180,327 \\
\hline Logo & 57 & 1,296 & 1 & 73,848 & 0 & - & 58 & 1273 & 73,848 \\
\hline Makurdi & 50 & 4,798 & 21 & 11,423 & 2 & 133,245 & 73 & 3286 & 239,889 \\
\hline Obi & 26 & 2,640 & 1 & 68,648 & 0 & - & 27 & 2543 & 68,648 \\
\hline Ogadibo & 60 & 1,492 & 1 & 89,497 & 0 & - & 61 & 1467 & 89,497 \\
\hline Ohimini & 29 & 1,158 & 0 & - & 0 & - & 29 & 1158 & 33,577 \\
\hline OJU & 46 & 2,236 & 4 & 25,719 & 0 & - & 50 & 2058 & 102,877 \\
\hline Okpokwu & 27 & 3,342 & 1 & 90,241 & 0 & - & 28 & 3223 & 90,241 \\
\hline Otukpo & 67 & 2,368 & 11 & 14,426 & 0 & - & 78 & 2034 & 158,681 \\
\hline Tarka & 28 & 1,521 & 1 & 42,591 & 0 & - & 29 & 1469 & 42,591 \\
\hline Ukum & 61 & 2,713 & 6 & 27,582 & 0 & - & 67 & 2470 & 165,490 \\
\hline Ushongo & 77 & 1,600 & 3 & 41,055 & 0 & - & 80 & 1540 & 123,166 \\
\hline Vandeikya & 56 & 2,890 & 3 & 53,954 & 0 & - & 59 & 2743 & 161,863 \\
\hline Total & 1,161 & 2,371 & 80 & 34,413 & 2 & $1,376,539$ & 1,243 & 2,215 & $2,753,077$ \\
\hline
\end{tabular}

Source: Field work, 2007.

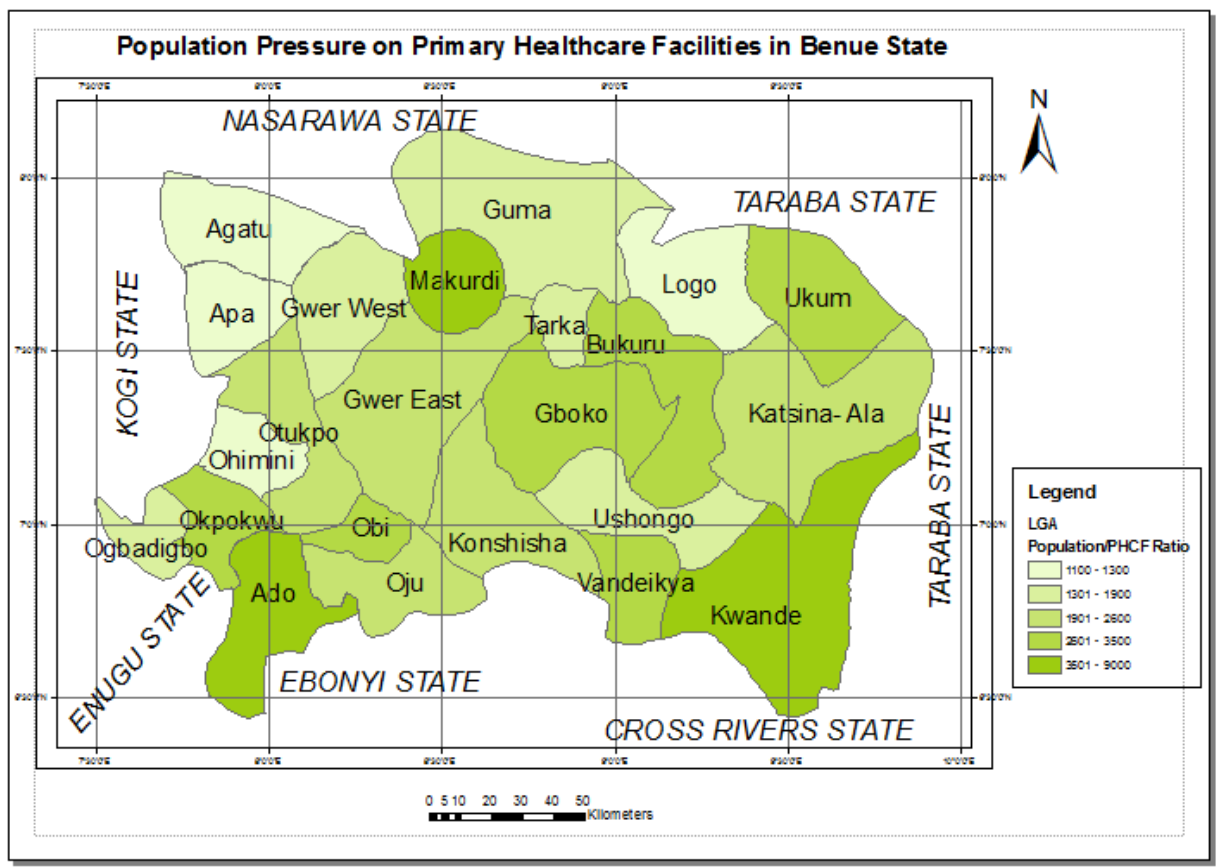

Fig. (10). Population-Primary Healthcare Facility Ratio. [Source: Authors' analysis]. 


\section{CONFLICT OF INTEREST}

The authors confirm that this article content has no conflict of interest.

\section{ACKNOWLEDGEMENTS}

The Authors are grateful to Strengthening Nigeria's Initiative for HIV/AIDS Response for permitting the use of their raw data.

\section{REFERENCES}

[1] Okafor SI. Intra Urban Pattern of Accessibility to Hospitals: A Nigerian case study. A research report funded by the Social Science Council of Nigeria (Ford II Project) 1990.

[2] FMOH. National AIDS/STD Control Programme Report. Department of Public Health, Federal Ministry of Health, Abuja 2001.

[3] Avert International AIDS Charity. Information of HIV and AIDS. 2006; www.avert.org

[4] NACA. The National HIV and AIDS Monitoring and Evaluation Plan 2011-2016. National Agency for the Control of AIDS, Abuja, Nigeria 2011; p. 227.

[5] Mafeni JO, Fajemisin OA. HIV/AIDS in Nigeria, situation, Response and prospects. Policy Project Nigeria 2003; p. 32.

[6] Jackson H. AIDS Africa: Continent in Crisis. Harare, South Africa 2002; pp. 55-80.

[7] Lampety P, Wigley M, Carr D, Collyrnore Y. Facing the HIV/AIDS pandemic. Popul Bull 2002; 57(3): 22-9.
[8] Pallela FJ, Delaney KM, Moorman AC, et al. Declining morbidity and mortality among patients with advanced human immunodeficiency virus infection. HIV Outpatient Study Investigators. N Engl J Med 1998; 338(13): 853-60.

[9] Tarantola D. Rethinking HIV/AIDS Risk, Impact and Vulnerability. Bull World Health Organon 2000; Vol. 78.

[10] PEPFAR. Partnership framework on HIV/AIDS, 2010-2015: memorandum of understanding between the Government of Nigeria and the United States Government to Fight HIV/AIDS in Nigeria 2010; p. 19.

[11] UNAIDS A Report on the UNGASS Indicators in Nigeria: A Follow-Up to the Declaration of Commitment on HIV/AIDS 2002.

[12] WHO Treating 3 million by 2005: Making it Happen: The WHO and UNAIDS Global Initiative to Provide Antiretroviral Therapy to 3 Million People with HIV/AIDS in Developing Countries by the end of 2005. World Health Organisation, Geneva 2003; p. 55.

[13] WHO. Report on Mission to Support the Antiretroviral Programme in Nigeria, WHO Draft Interim Report 2002.

[14] UNAIDS/WHO. Improving Access to Care in Developing Countries: Lessons from practice, research, Resources and Partnerships. Report from a meeting advocating for access to care and sharing experiences November 29 - December 1, 2001, Paris, France. Joint United Nations Program on HIV/AIDS/Ministry of Foreign Affairs, France 2002; p. 140.

[15] UNAIDS/WHO. Epidemiological Fact sheet on HIV/AIDS and Sexually Transmitted Infections, Nigeria. Joint United Nations Programme on HIV/AIDS 2004; p. 20.

[16] NISER. Costing of HIV/AIDS Prevention Initiatives in Nigeria. In: Ajakaiye DO, Makinwa PK, Odumosu OF, Eds. Nigerian Institute of Social and Economic Research (NISER), Ibadan. 2002; p. 189

[17] Ajala AO, Babatimehin O. Impacts of HIV/AIDS on Household, In: Ajakaiye DO, Odumosu OF, Eds. Socio-Economic Burdens of HIV/AIDS Epidemic in Nigeria, Nigerian Institute of Social and Economic Research (NISER), Ibadan 2002; pp. 87-103. 